\title{
The relationship between distorted body image and lifestyle among Japanese adolescents: a population-based study
}

Takako Shirasawa ${ }^{1 *}$, Hirotaka Ochiai ${ }^{1}$, Hinako Nanri ${ }^{1}$, Rimei Nishimura ${ }^{2}$, Tadahiro Ohtsu ${ }^{1}$, Hiromi Hoshino ${ }^{1}$, Naoko Tajima ${ }^{3}$ and Akatsuki Kokaze ${ }^{1}$

\begin{abstract}
Background: Distorted body image plays a significant role in the development of obesity, eating problems, and eating disorders. The aim of this study was to investigate the relationship between distorted body image and lifestyle among Japanese adolescent boys and girls.

Methods: Subjects were 1731 seventh graders (age 12-13 years) from the Ina-town's junior high schools, Japan, from 2005-2009. The height and weight of each subject were measured. Childhood underweight, overweight, and obesity were defined using the body mass index cutoff points proposed by the International Obesity Task Force. Information regarding the self-perceived weight status and lifestyles (exercise, snacking after dinner, breakfast, wakeup time, bedtime) of each subject was collected using a self-administered questionnaire. Self-perceived weight status was categorized into three groups (thin, normal, or heavy), and compared with the subjects' actual weight status. Body image perception was categorized into the following three groups: an underestimated own weight status group (underestimated group), a correct own weight status group (correct group) and an overestimated own weight status group (overestimated group).
\end{abstract}

Results: The proportion of boys in the underestimated group was higher than that of girls, while the opposite was true for the overestimated group $(P<0.001)$. There were no statistically significant differences in lifestyle between the underestimated group and the correct group regardless of sex. In contrast, there were statistically significant differences between the overestimated group and the correct group in the lifestyle factors of exercise among boys and snacking after dinner among girls. The adjusted odds ratio $(\mathrm{OR})$ in boys who exercised daily significantly decreased (OR: 0.35, $95 \%$ Cl: 0.16-0.77), while a significantly increased OR was observed in girls who snacked after dinner (OR: 1.53, $95 \% \mathrm{Cl}: 1.07-2.19)$.

Conclusion: Adolescent boys tended to underestimate their body weight, whereas adolescent girls were likely to overestimate their body weight. Furthermore, lifestyle factors associated with distorted body image differed by sex, with exercise affecting body image perception among boys and snacking after dinner affecting body image perception among girls. Thus, lifestyle may lead to distorted body image among adolescents.

Keywords: Distorted body image, Lifestyle, Adolescent, Sex, Japanese

\footnotetext{
* Correspondence: shirasawa@med.showa-u.ac.jp

'Department of Public Health, Showa University School of Medicine, Tokyo, Japan

Full list of author information is available at the end of the article
} 


\section{Background}

Childhood overweight and obesity have increased dramatically in economically developed countries and in urbanized populations [1]. In Japan, Matsushita et al. showed increasing trends in obesity prevalence in school children [2]. However, Inokuchi et al. reported that the prevalence of thinness among Japanese adolescents has progressively increased [3, 4]. Because thinness, overweight and obesity in adolescence have several adverse effects on health [5, 6], these are serious public health issues.

Body image plays a significant role in the development of obesity [7], eating problems, and eating disorders [8]. Some studies have reported that distorted body image was an important factor related to abnormal eating attitudes and behaviors among young people [9-11]. Kiriike et al. showed that the body mass index (BMI) of adolescents in Japan has decreased and that body shape has become thinner as a result of dieting in order to become slim [12]. Therefore, body image is an important factor for healthy body weight.

The relationship between body image and lifestyle factors, such as physical activity and eating behavior, among adolescents has been reported from many countries [13-18]. To the best of our knowledge, only one study examined the relationship between a distorted perception of body image and lifestyle factors (breakfast, snack, night snack, eating speed, eating amount, wakeup time, bedtime, exercise) in Japanese adolescent girls [19], while there have been no studies on this association among adolescent boys. Because body image is reported to be a strongly gendered phenomenon [20], it is necessary to investigate the relationship between distorted body image and lifestyle for each sex among adolescents.

Accordingly, the aim of this study was to investigate the relationship between distorted body image and lifestyle for each sex in Japanese adolescents.

\section{Methods \\ Subjects}

As a part of its community health services, the town of Ina in Saitama Prefecture, Japan has provided a unique health promotion program to prevent childhood lifestylerelated diseases since 1994, in addition to the annual national health checkups performed in accordance with the School Health Law of Japan. The program consists of a questionnaire survey and physical examinations for fourth and seventh graders. The present study was conducted as a part of this program. The study subjects comprised all seventh graders (age 12-13 years) from Ina-town's junior high schools from 2005 to $2009(N=1821)$. Written informed consent was obtained from each child's parent or guardian. The study protocol was approved by the Medical Ethics Committee of Showa University School of Medicine.

\section{Anthropometric measurements}

Measurements of height and weight for each child were performed annually during 2005-2009. The same examination protocol was used annually to ensure uniformity of quality and precision of assessment. For the measurements, all children were asked to remove their shoes and socks, after which their height and weight were measured in increments of $0.1 \mathrm{~cm}$ and $0.1 \mathrm{~kg}$, respectively, while they were wearing light clothing. BMI was calculated as body weight $(\mathrm{kg})$ divided by the square of the height $\left(\mathrm{m}^{2}\right)$. Childhood underweight, overweight, and obesity were defined using the BMI cutoff points (i.e., the age- and sex-specific cutoff points that were linked to BMI values of 18.5, 25 and 30 at age 18, respectively) proposed by the International Obesity Task Force [21-23]. The BMI cut-off points were based on averaging data from six countries including Asian countries, and the cut-off points were shown to be applicable to Japanese children [24]. In the present study, the BMI cut-off points for childhood underweight, overweight, and obesity were 15.35, 21.22, and 26.02 (age 12) and 15.84, 21.91, and 26.84 (age 13) for boys, and 15.62, 21.68, and 26.67 (age 12) and 16.26, 22.58, and 27.76 (age 13) for girls, respectively. In the present study, obesity was included in overweight. Children who were not underweight or overweight were regarded as normal weight. Therefore, each subject in this study was categorized into one of three actual weight status categories (underweight, normal weight, or overweight).

\section{Body image perception}

Self-perceived weight status was assessed using the following question on a self-administered questionnaire given to each child: "Do you think you are very thin, thin, normal weight, heavy, or very heavy?" Self-perceived weight status was then categorized into three groups: thin ("very thin" and "thin"), normal ("normal weight") and heavy ("heavy" and "very heavy"). Based on a comparison between the self-perceived weight status (thin, normal, or heavy) of each subject and his or her actual weight status (underweight, normal, or overweight), body image perception was categorized into the following three groups: an underestimated own weight status group (underestimated group), a correct own weight status group (correct group) and an overestimated own weight status group (overestimated group). For instance, subjects with a normal weight who perceived themselves as thin were included in the underestimated group, while those who perceived themselves as heavy were included in the overestimated group. Underestimated weight or overestimated weight were regarded as distorted body images in the present study.

\section{Lifestyle factors}

Information on the following lifestyle factors was obtained using a self-reported questionnaire given to each 
subject: snacking after dinner, and exercise other than physical education class. Each subject's parent or guardian was asked to complete a self-administered questionnaire regarding the breakfast, wakeup time and bedtime of each subject. Sleeping hours were calculated from wakeup time and bedtime.

\section{Statistical analysis}

The unpaired $t$-test or chi-squared test was used to compare characteristics between boys and girls. In the analysis stratified by sex, lifestyle factors in the correct group were compared with those in the underestimated and overestimated groups. Adjusted odds ratios (ORs) and $95 \%$ confidence intervals (CIs) were calculated by logistic regression. A $P$ value of less than 0.05 was considered statistically significant. All data were analyzed using SPSS 20.0J (IBM, Chicago, IL, USA).

\section{Results}

Among the 1821 children, 21 refused to participate in the program (participation rate: $98.8 \%$ ), and 69 were excluded due to missing data on anthropometric measurements and self-perceived weight status. Thus, data from a total of 1731 children ( 885 boys and 846 girls) were analyzed. The characteristics of the subjects are shown in Table 1. There was no statistically significant difference between boys and girls in actual weight status (underweight, normal weight, overweight) $(P=0.116)$. Self-perceived weight status and body image perception were statistically significantly different between boys and girls, respectively $(P<0.001)$. The proportion of boys in the underestimated group was higher than that of girls,
Table 1 Characteristics of study participants by sex (Japan; 2005-2009)

\begin{tabular}{lllr}
\hline Variable & $\begin{array}{l}\text { Boys } \\
(n=885)\end{array}$ & \multicolumn{1}{l}{$\begin{array}{l}\text { Girls } \\
(n=846)\end{array}$} & P-value \\
\hline Age (years) & $12.3(0.4)$ & $12.3(0.4)$ & 0.631 \\
Height $(\mathrm{cm})$ & $154.4(8.1)$ & $152.5(6.0)$ & $<0.001$ \\
Weight $(\mathrm{kg})$ & $44.5(9.7)$ & $43.6(7.9)$ & 0.040 \\
Body mass index $\left(\mathrm{kg} / \mathrm{m}^{2}\right)$ & $18.5(3.0)$ & $18.7(2.7)$ & 0.276 \\
Actual weight (\%) & & & \\
$\quad$ Underweight & $73(8.2)$ & $88(10.4)$ & 0.116 \\
$\quad$ Normal weight & $694(78.4)$ & $666(78.7)$ & \\
$\quad$ Overweight & $118(13.3)$ & $92(10.9)$ & \\
Self-perceived weight status (\%) & & & \\
$\quad$ Thin & $268(30.3)$ & $139(16.4)$ & $<0.001$ \\
$\quad$ Normal & $484(54.7)$ & $506(59.8)$ & \\
$\quad$ Heavy & $133(15.0)$ & $201(23.8)$ & \\
Body image perception (\%) & & & \\
$\quad$ Underestimated & $230(26.0)$ & $99(11.7)$ & $<0.001$ \\
$\quad$ Correct & $605(68.4)$ & $591(69.9)$ & \\
$\quad$ Overestimated & $50(5.6)$ & $156(18.4)$ & \\
\hline
\end{tabular}

Data are expressed as numbers (\%), values are means (standard deviation) The unpaired $t$-test and chi-squared test were used to compare characteristics between boys and girls

whereas the proportion of girls in the overestimated group was higher than that of boys $(P<0.001)$. About $70 \%$ of the children perceived their actual weight status correctly regardless of sex.

Figure 1 shows the relationship between actual weight status and self-perceived weight status by sex. Over $90 \%$

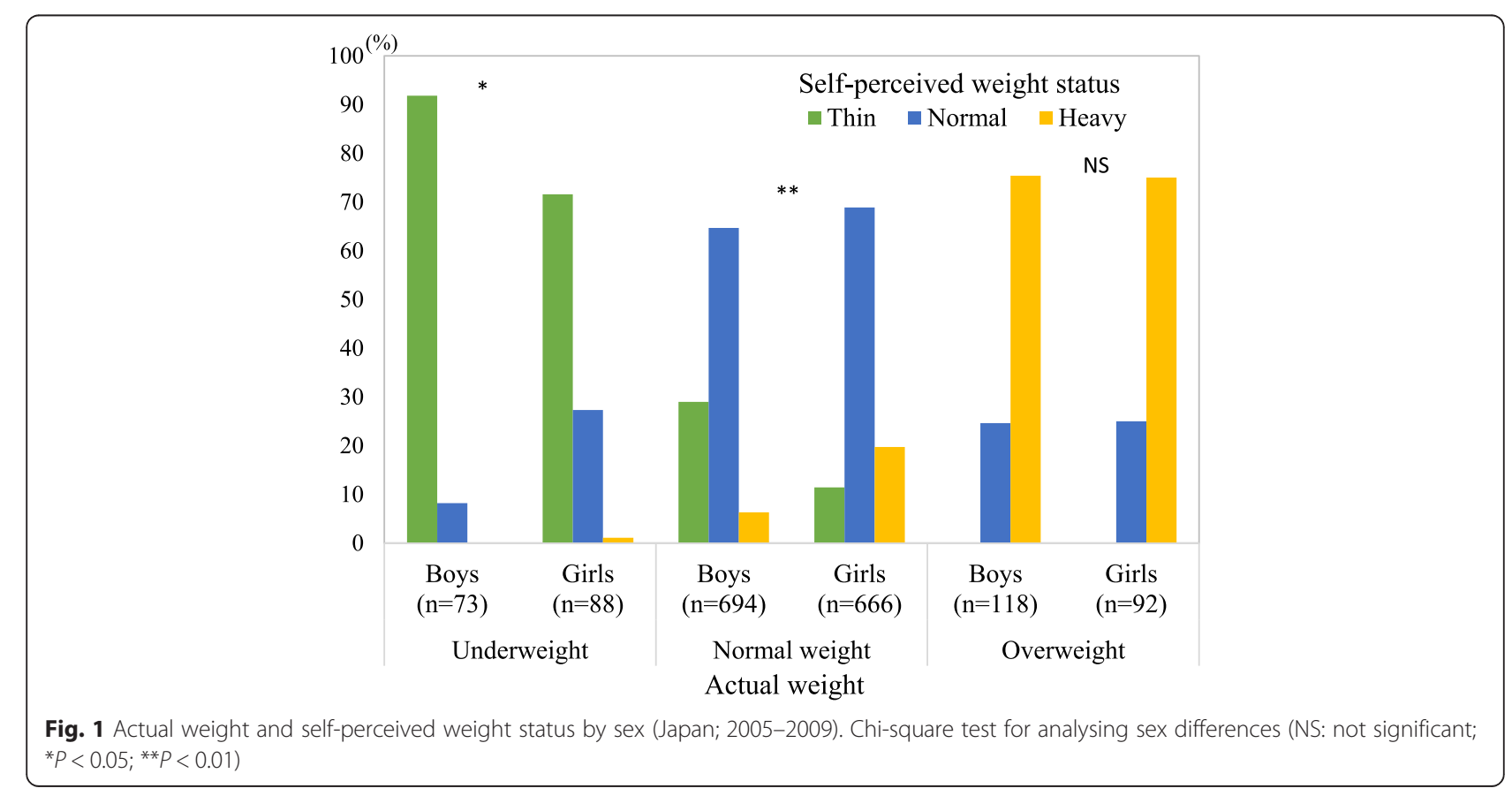


of underweight boys perceived themselves as thin, whereas about $30 \%$ of underweight girls perceived themselves as normal or heavy. In addition, approximately $30 \%$ of normal weight boys underestimated their actual weight status. In contrast, about $20 \%$ of normal weight girls overestimated their actual weight status. Among overweight children, over $20 \%$ underestimated their actual weight status regardless of sex.

The relationship between lifestyle and body image perception by sex are shown in Tables 2, 3, 4 and 5 . There were no statistically significant differences in lifestyle between the underestimated group and the correct group regardless of sex (Tables 2 and 3). In contrast, there were statistically significant differences between the overestimated group and the correct group in the lifestyle factors of exercise among boys (Table 4) and snacking after dinner among girls (Table 5). The adjusted odds ratio (OR) in boys who exercised daily significantly decreased (OR: 0.35, 95 \% CI: 0.16-0.77),

Table 2 Relationship between lifestyle factors and distorted body image (underestimation) among boys (Japan; 2005-2009)

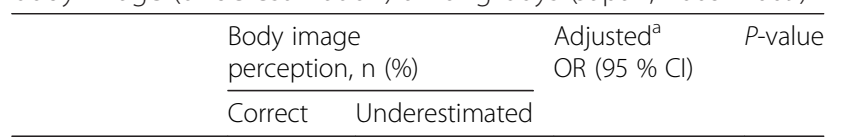

\begin{tabular}{lrrll}
\hline Exercise & & & & \\
Daily & $507(86.7)$ & $188(85.8)$ & $0.85(0.46-1.57)$ & 0.609 \\
Sometimes & $35(6.0)$ & $14(6.4)$ & $0.84(0.36-2.00)$ & 0.699 \\
Never & $43(7.4)$ & $17(7.8)$ & 1.00 &
\end{tabular}

Snacking after dinner

$\begin{array}{lllll}\text { Yes } & 314(52.7) & 121(54.0) & 1.05(0.76-1.44) & 0.774 \\ \text { No } & 282(47.3) & 104(46.0) & 1.00\end{array}$

Skipping breakfast

$\begin{array}{lrrlr}\text { No } & 568(95.5) & 216(95.2) & 1.00 & \\ \text { Yes } & 27(4.5) & 11(4.8) & 1.10(0.53-2.29) & 0.795\end{array}$

Wakeup time

$\begin{array}{lrrll}\text { Before 6:30 } & 298(52.6) & 111(49.6) & 1.00 & \\ \text { 6:30-6:59 } & 84(14.8) & 34(15.2) & 1.24(0.77-1.98) & 0.374 \\ \text { After 7:00 } & 185(32.6) & 79(35.3) & 1.20(0.84-1.70) & 0.319\end{array}$
Bedtime

$\begin{array}{lrrll}\text { Before 22:00 } & 58(10.6) & 24(11.0) & 1.00 & \\ \text { 22:00-22:59 } & 298(54.7) & 119(54.6) & 1.00(0.59-1.70) & 1.000 \\ \text { After 23:00 } & 189(34.7) & 75(34.4) & 1.05(0.60-1.83) & 0.867\end{array}$
Hours of sleep

$\begin{array}{llrll}<8 & 110(20.6) & 44(20.4) & 1.00 & \\ 8-9 & 302(56.7) & 120(55.6) & 0.92(0.61-1.40) & 0.705 \\ 9+ & 121(22.7) & 52(24.1) & 0.99(0.61-1.61) & 0.964\end{array}$

OR, odds ratio; $95 \% \mathrm{Cl}, 95 \%$ confidence interval

${ }^{a}$ Age and body mass index were adjusted in a logistic regression analysis
Table 3 Relationship between lifestyle factors and distorted body image (underestimation) among girls (Japan; 2005-2009)

\begin{tabular}{|c|c|c|c|c|}
\hline & \multicolumn{2}{|c|}{$\begin{array}{l}\text { Body image } \\
\text { perception, n (\%) }\end{array}$} & \multirow[t]{2}{*}{$\begin{array}{l}\text { Adjusted }^{\mathrm{a}} \\
\text { OR }(95 \% \mathrm{Cl})\end{array}$} & \multirow[t]{2}{*}{$P$-value } \\
\hline & Correct & Underestimated & & \\
\hline \multicolumn{5}{|l|}{ Exercise } \\
\hline Daily & $343(60.0)$ & 63 (65.6) & $1.28(0.76-2.16)$ & 0.346 \\
\hline Sometimes & 68 (11.9) & 10 (10.4) & $1.05(0.47-2.35)$ & 0.903 \\
\hline Never & $161(28.1)$ & $23(24.0)$ & 1.00 & \\
\hline \multicolumn{5}{|l|}{$\begin{array}{l}\text { Snacking after } \\
\text { dinner }\end{array}$} \\
\hline Yes & $276(47.8)$ & $56(57.1)$ & $1.44(0.93-2.23)$ & 0.100 \\
\hline No & $302(52.2)$ & $42(42.9)$ & 1.00 & \\
\hline \multicolumn{5}{|l|}{$\begin{array}{l}\text { Skipping } \\
\text { breakfast }\end{array}$} \\
\hline No & $548(93.4)$ & 91 (91.9) & 1.00 & \\
\hline Yes & $39(6.6)$ & $8(8.1)$ & $1.33(0.60-2.98)$ & 0.485 \\
\hline \multicolumn{5}{|l|}{ Wakeup time } \\
\hline Before 6:30 & 318 (55.8) & $45(46.4)$ & 1.00 & \\
\hline $6: 30-6: 59$ & $90(15.8)$ & $17(17.5)$ & $1.36(0.74-2.51)$ & 0.329 \\
\hline After 7:00 & $162(28.4)$ & $35(36.1)$ & $1.62(1.00-2.64)$ & 0.052 \\
\hline \multicolumn{5}{|l|}{ Bedtime } \\
\hline Before 22:00 & $36(6.7)$ & $9(9.5)$ & 1.00 & \\
\hline 22:00-22:59 & $262(48.4)$ & $46(48.4)$ & $0.73(0.33-1.63)$ & 0.445 \\
\hline After 23:00 & $243(44.9)$ & $40(42.1)$ & $0.72(0.32-1.63)$ & 0.435 \\
\hline \multicolumn{5}{|l|}{ Hours of sleep } \\
\hline$<8$ & 176 (32.8) & $22(23.4)$ & 1.00 & \\
\hline $8-9$ & $288(53.7)$ & $54(57.4)$ & $1.44(0.85-2.46)$ & 0.179 \\
\hline $9+$ & $72(13.4)$ & $18(19.1)$ & $1.85(0.93-3.67)$ & 0.081 \\
\hline
\end{tabular}

while a significantly increased OR was observed in girls who snacked after dinner (OR: 1.53, 95 \% CI: 1.07-2.19). There were no statistically significant associations between overestimated body weight image and wakeup time, bedtime, or sleeping hours in either sex.

\section{Discussion}

The present study demonstrated that about $70 \%$ of children evaluated their actual weight status appropriately regardless of sex. It follows from this that $30 \%$ of adolescent boys and girls overestimated or underestimated their actual weight status. In addition, adolescent boys tended to underestimate their body weight, whereas adolescent girls were more likely to overestimate their body weight, findings consistent with previous results [25-27]. In a previous study, the desire for thinness and fear of weight gain were shown in significant proportions of preadolescent girls and progressively increased to include the majority of adolescent girls [28]. Among girls, the preference for an 
Table 4 Relationship between lifestyle factors and distorted body image (overestimation) among boys (Japan; 2005-2009)

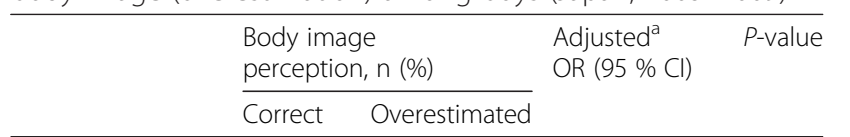

Exercise

$\begin{array}{lllll}\text { Daily } & 507(86.7) & 37(75.5) & 0.35(0.16-0.77) & 0.009 \\ \text { Sometimes } & 35(6.0) & 3(6.1) & 0.41(0.10-1.65) & 0.210 \\ \text { Never } & 43(7.4) & 9(18.4) & 1.00 & \end{array}$

Snacking after

dinner

\begin{tabular}{|c|c|c|c|}
\hline Yes & $314(52.7)$ & $22(44.0)$ & $0.69(0.39-1.24)$ \\
\hline No & $282(47.3)$ & $28(56.0)$ & 1.00 \\
\hline
\end{tabular}

Skipping breakfast

$\begin{array}{lllll}\text { No } & 568(95.5) & 45(91.8) & 1.00 & \\ \text { Yes } & 27(4.5) & 4(8.2) & 1.87(0.63-5.59) & 0.262\end{array}$

Wakeup time

$\begin{array}{lllll}\text { Before 6:30 } & 298(52.6) & 23(46.9) & 1.00 & \\ \text { 6:30-6:59 } & 84(14.8) & 7(14.3) & 1.09(0.45-2.65) & 0.842 \\ \text { After 7:00 } & 185(32.6) & 19(38.8) & 1.31(0.69-2.48) & 0.403\end{array}$

Bedtime

$\begin{array}{lllll}\text { Before 22:00 } & 58(10.6) & 3(6.8) & 1.00 & \\ \text { 22:00-22:59 } & 298(54.7) & 26(59.1) & 1.63(0.48-5.59) & 0.434 \\ \text { After 23:00 } & 189(34.7) & 15(34.1) & 1.46(0.41-5.25) & 0.561\end{array}$

Hours of sleep

\begin{tabular}{lllll}
$<8$ & $110(20.6)$ & $7(15.9)$ & 1.00 & \\
$8-9$ & $302(56.7)$ & $28(63.6)$ & $1.45(0.61-3.42)$ & 0.397 \\
$9+$ & $121(22.7)$ & $9(20.5)$ & $1.20(0.43-3.35)$ & 0.722 \\
\hline
\end{tabular}

OR odds ratio, $95 \% \mathrm{Cl} 95 \%$ confidence interval

${ }^{\mathrm{a}} \mathrm{Age}$ and body mass index were adjusted in a logistic regression analysis

extremely slim body might have roots in the lack of proper understanding of average body weight, which might also be affected by the fact that they set their ideal shape at a level that is even lower than their misunderstood average [29]. In contrast to the girls who want to be slim, adolescent boys might be increasingly concerned with becoming more muscular [20]. Therefore, sex differences in body image perception could be due to the difference in body preference between boys and girls.

In this study, no significant relationship between distorted body image (underestimated weight) and lifestyle was observed among either sex. The results suggested that the lifestyle of adolescents in the underestimated group was similar to that of adolescents in the correct group regardless of sex. However, because adolescents in the underestimated group did not estimate their actual body weight accurately, their distorted body image might have adverse effects on their future health.

In contrast, distorted body image (overestimated weight) was significantly associated with some lifestyle factors.
Table 5 Relationship between lifestyle factors and distorted body image (overestimation) among girls (Japan; 2005-2009)

\begin{tabular}{|c|c|c|c|c|}
\hline & \multicolumn{2}{|c|}{$\begin{array}{l}\text { Body image } \\
\text { perception, } n(\%)\end{array}$} & \multirow[t]{2}{*}{$\begin{array}{l}\text { Adjusted }^{\mathrm{a}} \\
\text { OR }(95 \% \mathrm{Cl})\end{array}$} & \multirow[t]{2}{*}{$P$-value } \\
\hline & Correct & Overestimated & & \\
\hline \multicolumn{5}{|l|}{ Exercise } \\
\hline Daily & $343(60.0)$ & 81 (52.9) & $0.87(0.58-1.32)$ & 0.523 \\
\hline Sometimes & 68 (11.9) & 28 (18.3) & $1.51(0.87-2.62)$ & 0.147 \\
\hline Never & $161(28.1)$ & 44 (28.8) & 1.00 & \\
\hline \multicolumn{5}{|l|}{$\begin{array}{l}\text { Snacking after } \\
\text { dinner }\end{array}$} \\
\hline Yes & $276(47.8)$ & $90(58.4)$ & $1.53(1.07-2.19)$ & 0.021 \\
\hline No & $302(52.2)$ & $64(41.6)$ & 1.00 & \\
\hline \multicolumn{5}{|l|}{ Skipping breakfast } \\
\hline No & $548(93.4)$ & 147 (95.5) & 1.00 & \\
\hline Yes & $39(6.6)$ & $7(4.5)$ & $0.67(0.30-1.54)$ & 0.347 \\
\hline \multicolumn{5}{|l|}{ Wakeup time } \\
\hline Before 6:30 & $318(55.8)$ & $89(59.7)$ & 1.00 & \\
\hline 6:30-6:59 & $90(15.8)$ & 25 (16.8) & $0.98(0.60-1.63)$ & 0.950 \\
\hline After 7:00 & $162(28.4)$ & $35(23.5)$ & $0.76(0.49-1.17)$ & 0.215 \\
\hline \multicolumn{5}{|l|}{ Bedtime } \\
\hline Before 22:00 & $36(6.7)$ & $8(5.8)$ & 1.00 & \\
\hline $22: 00-22: 59$ & $262(48.4)$ & $66(47.8)$ & $1.12(0.50-2.54)$ & 0.780 \\
\hline After 23:00 & $243(44.9)$ & $64(46.4)$ & $1.15(0.51-2.60)$ & 0.738 \\
\hline \multicolumn{5}{|l|}{ Hours of sleep } \\
\hline$<8$ & $176(32.8)$ & 49 (35.8) & 1.00 & \\
\hline $8-9$ & $288(53.7)$ & $72(52.6)$ & $0.92(0.61-1.38)$ & 0.672 \\
\hline $9+$ & $72(13.4)$ & $16(11.7)$ & $0.82(0.44-1.55)$ & 0.544 \\
\hline
\end{tabular}

Although previous studies have reported the association between lifestyle factors (diet, physical activity habits and sedentary behaviors) and overweight/obesity among adolescents [24, 30,31], these lifestyle factors were related to distorted body image independently of actual BMI in this study. Moreover, the impact of lifestyle on overestimating body weight varied by sex; overestimated body weight was positively associated with snacking after dinner among girls, while it was negatively associated with exercise behavior among boys. Boys with regular exercise habits might not tend to overestimate their body weight, which may have been the reason for the low OR for overestimated body weight in this study. Adolescent girls who overestimated their body weight tended to snack after dinner, a finding consistent with a previous study [32]. Among adolescent girls, eating faster and not eating breakfast on a daily basis were identified as being associated with overestimated body weight [19]. These findings suggest that the presence of such unhealthy behaviors during adolescence might 
have long-term detrimental effects on body image in both sexes.

Most studies about body image among Japanese adolescents have used self-reported weight and height to calculate BMI, which has been reported to be inaccurate [8]. In contrast, the height and weight of over 1800 population-based schoolchildren were measured at a high participation rate (over $98 \%$ ) in our study, which was its main strength. However, the present study also had some limitations. First, this study did not consider socio-economic status [32] and psychological factors [33], which have been shown to influence weight perception. Second, the subjects in this study were seventh graders (12-13 years of age) from one town in Japan, which might limit generalizability to other Japanese schoolchildren or other races. Finally, the present study could not determine a causal relationship between a distorted body image and lifestyle since this was a cross-sectional study. Therefore, the possibility of reverse causality cannot be denied.

\section{Conclusions}

The present study found that adolescent boys tended to underestimate their body weight, whereas adolescent girls were likely to overestimate their body weight. Furthermore, lifestyle factors associated with a distorted body image differed by sex, with exercise affecting perception among boys and snacking after dinner affecting perception among girls. Thus, lifestyle may lead to distorted body image among adolescents. Therefore, sex differences should be considered when educating adolescents on accurate weight perception, which could contribute to public health strategies to curb the increasing prevalence of underweight and overweight/ obesity in Japan.

\section{Competing interests}

The authors declare that they have no competing interests.

\section{Authors' contributions}

TS and HO planned this study. RN contributed to improving this study in a meaningful way. TS drafted this manuscript. $\mathrm{HO}, \mathrm{RN}$, and $\mathrm{HH}$ collected the data. HO supervised the data collection. TO supported the data collection. $\mathrm{HO}$ and $\mathrm{HN}$ contributed to the statistical analysis. NT and AK made substantial contributions to the conception of this study and the revision of the manuscript. All authors read and approved the final manuscript.

\section{Acknowledgments}

The authors would like to thank all study participants, their parents and guardians, all members of the Board of Education in Ina Town, Saitama Prefecture, and the Ina-machi Conference for the Promotion and Implementation of the Childhood Lifestyle-Related Disease Prevention Examination (Chairman: Dr. Yoshihito Toriyama). This study was supported in part by Grants-in-Aid from the Ministry of Education, Culture, Sports, Science, and Technology of Japan (2002-2004, No. 14207020; 2005-2008, No.17209024; and 2013-2015, No. 25350854)

\section{Author details}

'Department of Public Health, Showa University School of Medicine, Tokyo, Japan. ${ }^{2}$ Division of Diabetes, Metabolism and Endocrinology, Department of Internal Medicine, Jikei University School of Medicine, Tokyo, Japan. ${ }^{3}$ Jikei

University School of Medicine, Tokyo, Japan.

Received: 16 March 2015 Revised: 12 May 2015 Accepted: 29 May 2015 Published online: 20 July 2015

\section{References}

1. Wang Y, Lobstein T. Worldwide trends in childhood overweight and obesity. Int J Pediatr Obes. 2006;1(1):11-25.

2. Matsushita Y, Yoshiike N, Kaneda F, Yoshita K, Takimoto H. Trends in childhood obesity in Japan over the last 25 years from the national nutrition survey. Obes Res. 2004;12(2):205-14.

3. Inokuchi M, Matsuo N, Takayama Jl, Hasegawa T. Trends in thin body stature among Japanese female adolescents, 2003-2012. Ann Hum Biol. 2014: doi:10.3109/03014460.2014.975280.1-5.

4. Inokuchi M, Matsuo N, Takayama Jl, Hasegawa T. Trends in thin body stature among Japanese male adolescents, 2003-2012. Ann Hum Biol. 2014:41(3):277-81.

5. Baker JL, Olsen LW, Sorensen TI. Childhood body-mass index and the risk of coronary heart disease in adulthood. N Engl J Med. 2007;357(23):2329-37.

6. Patton GC, Selzer R, Coffey C, Carlin JB, Wolfe R. Onset of adolescent eating disorders: population based cohort study over 3 years. BMJ. 1999;318(7186):765-8.

7. Mogre V, Mwinlenna PP, Oladele J. Distorted self-perceived weight status and its associated factors among civil servants in Tamale, Ghana: a cross-sectional study. Arch Public Health. 2013;71(1):30.

8. Chisuwa N, O'Dea JA. Body image and eating disorders amongst Japanese adolescents. A review of the literature. Appetite. 2010;54(1):5-15.

9. Suka M, Sugimori H, Yoshida K, Kanayama H, Sekine M, Yamagami T, et al. Body image and body satisfaction play important roles in the path to dieting behavior in Japanese preadolescents: the Toyama birth cohort study. Environ Health Prev Med. 2005;10(6):324-30.

10. Makino M, Hashizume M, Yasushi M, Tsuboi K, Dennerstein L. Factors associated with abnormal eating attitudes among female college students in Japan. Arch Womens Ment Health. 2006;9(4):203-8.

11. Nakamura K, Hoshino Y, Watanabe A, Honda K, Niwa S, Tominaga K, et al. Eating problems in female Japanese high school students: a prevalence study. Int J Eat Disord. 1999;26(1):91-5.

12. Kiriike N, Nagata T, Sirata K, Yamamoto N. Are young women in Japan at high risk for eating disorders?: Decreased BMI in young females from 1960 to 1995. Psychiatry Clin Neurosci. 1998;52(3):279-81.

13. Chung AE, Perrin EM, Skinner AC. Accuracy of child and adolescent weight perceptions and their relationships to dieting and exercise behaviors: a NHANES study. Acad Pediatr. 2013;13(4):371-8.

14. Farah Wahida Z, Mohd Nasir MT, Hazizi AS. Physical activity, eating behaviour and body image perception among young adolescents in Kuantan, Pahang, Malaysia. Malays J Nutr. 2011;17(3):325-36.

15. Shi Z, Lien N, Nirmal Kumar B, Holmboe-Ottesen G. Perceptions of weight and associated factors of adolescents in Jiangsu Province. China Public Health Nutr. 2007;10(3):298-305.

16. Petracci E, Cavrini G. The effect of weight status, lifestyle, and body image perception on health-related quality of life in children: a quantile approach. Qual Life Res. 2013;22(9):2607-15.

17. Westerberg-Jacobson J, Edlund B, Ghaderi A. A 5-year longitudinal study of the relationship between the wish to be thinner, lifestyle behaviours and disturbed eating in 9-20-year old girls. Eur Eat Disord Rev. 2010;18(3):207-19.

18. Chen $X$, Wang Y. Is ideal body image related to obesity and lifestyle behaviours in African American adolescents? Child Care Health Dev. 2012;38(2):219-28.

19. Mori K, Sekine M, Yamagami T, Kagamimori S. Relationship between body image and lifestyle factors in Japanese adolescent girls. Pediatr Int. 2009:51(4):507-13.

20. Smolak L. Body image in children and adolescents: where do we go from here? Body Image. 2004;1(1):15-28.

21. Cole TJ, Bellizzi MC, Flegal KM, Dietz WH. Establishing a standard definition for child overweight and obesity worldwide: international survey. BMJ. 2000;320(7244):1240-3. 
22. Cole TJ, Flegal KM, Nicholls D, Jackson AA. Body mass index cut offs to define thinness in children and adolescents: international survey. BMJ. 2007;335(7612):194.

23. Cole TJ, Lobstein T. Extended international (IOTF) body mass index cut-offs for thinness, overweight and obesity. Pediatr Obes. 2012;7(4):284-94.

24. Sun Y, Sekine M, Kagamimori S. Lifestyle and overweight among Japanese adolescents: the Toyama Birth Cohort Study. J Epidemiol. 2009;19(6):303-10.

25. McCabe MP, Ricciardelli LA, Finemore J. The role of puberty, media and popularity with peers on strategies to increase weight, decrease weight and increase muscle tone among adolescent boys and girls. J Psychosom Res. 2002;52(3):145-53

26. Sano A, Le DS, Tran MH, Pham HT, Kaneda M, Murai E, et al. Study on factors of body image in Japanese and Vietnamese adolescents. J Nutr Sci Vitaminol (Tokyo). 2008;54(2):169-75

27. Nishizawa Y, Kida K, Nishizawa K, Hashiba S, Saito K, Mita R. Perception of self-physique and eating behavior of high school students in Japan. Psychiatry Clin Neurosci. 2003:57(2):189-96.

28. Kaneko K, Kiriike N, Ikenaga K, Miyawaki D, Yamagami S. Weight and shape concerns and dieting behaviours among pre-adolescents and adolescents in Japan. Psychiatry Clin Neurosci. 1999;53(3):365-71.

29. Matsuura K, Fujimura M, Nozawa Y, lida Y, Hirayama M. The body shape preferences of Japanese female students. Int J Obes Relat Metab Disord. 1992;16(2):87-93.

30. Farajian P, Panagiotakos DB, Risvas G, Malisova O, Zampelas A. Hierarchical analysis of dietary, lifestyle and family environment risk factors for childhood obesity: the GRECO study. Eur J Clin Nutr. 2014:68(10):1107-12.

31. Ochiai H, Shirasawa T, Ohtsu T, Nishimura R, Morimoto A, Hoshino H, et al. Eating behaviors and overweight among adolescents: a population-based survey in Japan. J Obes. 2013;2013:717942.

32. Xie B, Chou CP, Spruijt-Metz D, Reynolds K, Clark F, Palmer PH, et al. Weight perception and weight-related sociocultural and behavioral factors in Chinese adolescents. Prev Med. 2006;42(3):229-34.

33. Tang J, Yu Y, Du Y, Ma Y, Zhu H, Liu Z. Association between actual weight status, perceived weight and depressive, anxious symptoms in Chinese adolescents: a cross-sectional study. BMC Public Health. 2010;10:594.

\section{Submit your next manuscript to BioMed Central and take full advantage of:}

- Convenient online submission

- Thorough peer review

- No space constraints or color figure charges

- Immediate publication on acceptance

- Inclusion in PubMed, CAS, Scopus and Google Scholar

- Research which is freely available for redistribution 